\title{
THE RELIABILITY OF A WINDSHIELD SURVEY TO LOCATE HAZARDS IN ROADSIDE TREES
}

\author{
By C.J. Rooney ${ }^{1}$, H.D.P. Ryan², D.V. Bloniarz ${ }^{3}$, and B.C.P. Kane ${ }^{4}$
}

\begin{abstract}
Hazardous conditions in roadside trees are a constant concern for municipal arborists. Due to fiscal constraints, many municipalities desire an accurate and efficient method to inspect their tree populations. This case study shows that a windshield survey can be used to find hazardous conditions in roadside trees, using a simple system and an experienced Certified Arborist. In addition, the case study showed that the percentage of detected hazardous conditions increased as the conditions became more severe. The percentage of hazardous tree conditions found using a windshield survey in developed sample areas far exceeded those found in undeveloped sample areas.
\end{abstract}

Key Words. Windshield survey; hazard trees; municipal forestry; risk management.

Many municipalities are struggling financially. With budget shortfalls and increasing costs it is becoming more difficult for municipalities to deliver necessary services. Trees are often on the losing side when poor economic circumstances reduce municipal budgets, because tree planting and maintenance are not considered as important as other services. Unfortunately, many municipalities allocate neither the funding nor the time to take care of their trees properly, and at the same time society is becoming more litigious (Smiley and Fraedrich 1991). Such considerations prompt municipalities toward greater efficiency in community tree management. A consequent benefit of such an increase in efficiency is protecting the community from litigation. A community should exert a reasonable amount of effort toward caring for and inspecting their trees for hazards.

The objective of this case study was to compare a windshield survey for hazard trees to a traditional individual hazard tree inventory. Specifically, the case study investigated the accuracy and efficiency of both methods and attempted to identify conditions or situations that would favor one method over the other.

The hypothesis for the project is that windshield surveys can be reliably used to assess tree defects compared to a traditional walking inspection. To test the hypothesis, a windshield inventory of all town-maintained roads was conducted, then a traditional walking inspection of randomly selected samples of the trees was conducted.

A windshield survey is a method of evaluating trees whereby an arborist is driven along a community's roads recording certain tree characteristics. A windshield survey can save time over walking because the arborist is driven along a community's roads. Windshield surveys are most efficient when the arborist is looking for one or two particular tree characteristics. Windshield surveys have been and continue to be used in many cities and towns throughout the United States. The Urban Forestry Department in Cincinnati, Ohio, U.S., uses a windshield survey to inventory trees that records the species, size, and condition of the city's trees (Sandfort 2001). The main purpose of the type of windshield survey used in this case study was to identify hazardous tree conditions throughout the community and prioritize them based on probability of target impact, size of defective tree part, probability of failure of defective part, and tree species.

Many sources recommend annual inspections of trees (Grey and Deneke 1978; Kane et al. 2001; Lilly 2001). In a residential setting, tree inspections can include checking tree health and damaged or loose support cables. For a municipality, an annual tree inspection's main goal is to find tree hazards. Within a year, a tree's structural and physiological condition can change quite easily; weather, humans, insects, and diseases can be major factors that cause changes. Annual inspection of high-use areas such as heavily traveled roads or high-use public parks should help keep an arborist aware of changing situations. The results of an annual inspection can help an arborist plan and schedule upcoming maintenance. An annual inspection can also document that there is a systematic and standardized inspection protocol for assessing the community's trees. The standardized protocol for hazard assessment is necessary because a number of lawsuits have demonstrated that municipalities are directly responsible for the upkeep and the inspection of their trees.

\section{WINDSHIELD SURVEY ISSUES}

A municipality's options for inspecting the trees for hazardous conditions are (1) do nothing, (2) conduct a thorough walking inspection, (3) conduct a windshield survey, or (4) use a combination of techniques. Given the climate of litigation in the United States and recent court rulings as well as for concerns about public safety, it would be unwise not to inspect the trees, although many communities choose this option. Conducting a thorough, up-close inspection of all the trees in a community is not always feasible for many municipalities due to financial constraints. For instance, 
contractors in New England often charge approximately $\$ 5$ per tree to inspect for hazards. In addition, many municipalities lack the skilled labor needed to undertake a thorough inspection in-house. Conducting a windshield survey of certain areas presents another option for the municipality to save time and money.

The main problem with choosing the windshield survey option is that no one has examined the method's reliability at identifying roadside hazardous tree conditions. Many professionals in the tree care industry have questioned the validity of this hazard tree inspection method. The U.S. Park Service's Hazard Tree Guidelines note that "... the obvious limitations of the effectiveness of this method may not allow it to be very persuasive in a court of law, and only a thorough documentation of findings will lend any credence to this method" (National Park Service 1991). Many urban foresters and arborists feel that in certain situations a windshield survey will not work effectively. For instance, it may not work well in congested urban areas where the arborist's visibility may be poor or where the surrounding traffic conditions are difficult, causing some hazardous conditions to be missed. Other professionals feel that in any type of roadside situation, this method is unacceptable for a thorough hazard tree survey. This is due to the inability to effectively examine the tree from every angle and the inability to get close to the tree. "Subtle defects such as narrow cracks or girdling roots, even if they occur on the side facing the road, may go undetected simply because they cannot be readily seen from the road" (Pokorny 2003, p. 28).

\section{METHODOLOGY}

The community chosen for this case study was South Kingstown, Rhode Island, U.S. Located on the Atlantic coast in the southern part of the state, the town has vegetation types ranging from seaside scrublands in the southeast to mixed oak forest in the northwest. The town's population is approximately 28,000 people, and the town has approximately $217 \mathrm{~km}$ (135 mi) of maintained roads. The town employs a part-time tree warden, and the total population of municipally maintained trees in the town is estimated to be 15,000 to 20,000 . At the time of this case study, winter 2002-2003, the town had not yet implemented an annual hazard tree inspection program.

South Kingstown was ideal for testing the windshield survey method because it contains a variety of roadside environments. The town has a wide range of street and neighborhood settings, ranging from rural to urban. The variety of street and neighborhood layouts creates a similar variety of planting locations. Additionally, South Kingstown's tree population varies greatly. Trees managed by the town exhibit diverse conditions, species, and sizes, and some trees are extremely hazardous. The variety of neighborhoods and tree species, sizes, and conditions helped to test the effectiveness of a windshield survey over the range of variables.

\section{Windshield Survey}

The windshield survey of $100 \%$ of town roads was intended to accomplish several things. First, it provided the data set for comparison with the traditional walking inspection. Once the sample areas within the town were determined, the windshield survey dataset was broken down to the specific randomly selected areas and then comparisons would be made.

Second, the windshield survey was used to collect hazard tree data that would be given to the town's tree warden and the local electric company once the project was completed. Those data would be used to remediate hazard trees.

The windshield survey was also used to identify land use and road type. Roads, or road segments as necessary, were classified as, "developed," "undeveloped," or "no town trees present." Each classification had distinct characteristics. A developed road or road segment had town trees growing in front of homes or businesses with lawns, in utility planting strips between the road and sidewalk, or in planting pits in a sidewalk. An undeveloped road or road segment had no sidewalk or maintained lawn and had a woodland setting or an old stone wall delineating the setback distance. A road or road segment with no town trees present, or if the existing town trees were not worth resurveying due to their small size, would be classified as "no town trees." Such areas included new developments and older neighborhoods where the only trees were set back on private property. These areas were eliminated from the study. Each of the road types was used to create a stratified category to help determine sampling areas.

Prior to commencing the windshield survey, the following protocols were established:

1. Because the major objective of this windshield survey was the identification of hazardous conditions, it was conducted after leaf drop.

2. A pick-up truck or SUV was used to drive the inspector during the windshield survey.

3. The person who conducted the survey is an ISA Certified Arborist and a Rhode Island licensed arborist who sat in the front passenger seat during the surveys; prior to surveying, he had received training in locating and identifying tree defects.

4. Aside from a clean driver's license, the driver did not need any special qualifications, although familiarity with town roads was helpful.

A personal digital assistant (PDA) was used to record all of the survey data, and Pendragon Forms ${ }^{\circledR}$ software was used to create a data collection form. The PDA was chosen because of its ability to synchronize with a desktop computer for quick data importation. A PDA also has the ability to store lists. This saves time by allowing the surveyor to pick a particular item from a list, instead of repeatedly typing each item. 
The following data were collected for each hazard tree: tree genus and species, location, target, and tree defect. For each tree containing a hazardous condition, a hazard rating was given. The hazard rating system that was used was first developed by Pokorny in 1998 and modified by Ryan and Bloniarz in 2001 (Kane et al. 2001). The hazard rating was determined by four variables and ranged from 12 (severe hazard) to 3 (very small hazard). Tables 1, 2, and 3 describe thresholds for three of four variables used to determine hazard ratings, probability of target impact (Table 1), size of the defective part (Table 2 ), and probability of failure (Table 3 ). The fourth variable is species rating, which is based on a scale of 0 to 2 (the higher value increasing the hazard rating). Species rating is based on the collective experience of the authors (over 75 years) assessing tree risk and observing tree failures in New England. Species rating allowed the inspector to increase the hazard rating for common street trees that are prone to failure in New England, such as horsechestnut (Aesculus hippocastanum) and Bradford pear (Pyrus calleryana 'Bradford').

The scores for each variable were recorded and totaled for each tree, the total ranging from 3 to 12 . Trees with a hazard rating less than 6 were not recorded because they did not pose an immediate threat and were not hazards.

For the project, only trees that were within town rightsof-way were examined, so it was important to know the location and widths of all the rights-of-way. That information was acquired from the highway department.

One final logistical concern was the relative use of roadways during different days and times. For example,

\section{Table 1. Probability of target impact (1 to 3 points).}

\section{Occasional use ( 1 point)}

- low-use roadways (i.e., dead-end roads, turnarounds)

\section{Intermittent use ( 2 points)}

- roadway intersections in high-use areas

- $\quad$ parking lots adjacent to moderate- and low-use areas

- $\quad$ dispersed picnic areas

\section{Frequent use ( 3 points)}

- $\quad$ high-use roadway

- $\quad$ all buildings and residences

- $\quad$ schoolyards

- $\quad$ specially marked handicap-access areas

- $\quad$ parking lots

Table 2. Values for the size of the defective part ( 1 to 4 points).

1 point: parts less than $5.1 \mathrm{~cm}(2 \mathrm{in}$.) in diameter

2 points: parts from 5.1 to $25.4 \mathrm{~cm}$ (2 to $10 \mathrm{in}$.) in diameter

3 points: parts from 25.5 to $50.8 \mathrm{~cm}$ (10 to $20 \mathrm{in}$.) in diameter

4 points: parts greater than $50.8 \mathrm{~cm}$ (20 in.) in diameter
Table 3. Probability of failure (1 to 3 points).

Low: Some minor defects present ( 1 point)

- minor branch dieback

- minor defects or wounds

Moderate: One to several moderate defects present ( 2 points)

- $\quad$ stem decay or cavity within safe shell decay

- weak union with in-rolled bark

- $\quad$ defects(s) affecting less than 50\% of tree's circumference

- $\quad$ leaning tree (away from target area; greater than 45-degree angle) without new root lifting

High: Multiple or significant defects present ( 3 points)

- $\quad$ stem decay or cavity at shell safety limits

- multiple cracks or a single crack that goes completely through the stem

- $\quad$ weak union with crack or decay

- defect(s) affecting more than 50\% of tree's circumference, with decay present

- $\quad$ leaning tree (toward target area; greater than 45-degree angle) with recent root lifting or soil mounding

- dead or lodged branches; dead trees

streets on which schools are located cannot be inventoried at certain times because there is risk of traffic accidents.

If there were trees on both sides of the road, the inspector was driven up and down the road. If the trees were on one side only, it was necessary to cover the street in one direction only. The inspector indicated to the driver where to go, how fast to drive, and when to stop completely for the inspector to gather the tree information.

Once the windshield portion of the study was completed, a traditional walking survey was conducted for comparison. First, the resurvey sample areas were determined by taking random samples from each of the two stratified categories. Next, these sample areas were walked, and each tree was inspected. Care was taken to observe each tree from every angle. Following these inspections the two methods were compared.

\section{RESULTS \\ Windshield Survey Findings}

The 100\% windshield survey encompassed $214 \mathrm{~km}$ (133 mi) of town-maintained roads. The survey took 72.5 hours and was conducted over the course of 20 nonconsecutive days. The survey yielded a total of 1,116 trees with hazard ratings between 6 and 12. Table 4 shows the distribution of trees per hazard rating and the percentage of each rating category relative to the total. Most of the hazard trees (92\%) were rated between 6 and 10 , with only $8 \%$ of the hazard trees rated 11 and 12 . The vehicle used for the windshield survey was driven at an average speed of $3.06 \mathrm{~km} / \mathrm{h}(1.9$ $\mathrm{mph}$ ) during the entire survey. 
Table 4. Frequency distribution of trees per hazard rating and mean rating for trees found during the windshield survey.

\begin{tabular}{llll}
\hline Hazard rating & Number of trees & $\begin{array}{l}\text { Percentage } \\
\text { of total }\end{array}$ & $\begin{array}{l}\text { Cumulative } \\
\text { percentage }\end{array}$ \\
\hline 6 & 147 & $13 \%$ & $13 \%$ \\
7 & 252 & $23 \%$ & $36 \%$ \\
8 & 226 & $20 \%$ & $56 \%$ \\
9 & 247 & $22 \%$ & $78 \%$ \\
10 & 158 & $14 \%$ & $92 \%$ \\
11 & 68 & $6 \%$ & $98 \%$ \\
12 & 18 & $2 \%$ & $100 \%$ \\
Trees found & 1116 & & \\
Mean score & 8.3 & & \\
\hline
\end{tabular}

Comparison of Windshield and Walking Surveys

The total number of trees surveyed by walking was 329 . Table 5 shows the number of hazard trees found by the walking survey by rating category. Table 5 also shows the number of hazard trees in each rating category found by the windshield survey expressed as a percentage of hazard trees found by the walking survey.

Table 5. Comparison of windshield and walking survey hazard trees by hazard rating.

\begin{tabular}{lll}
\hline & $\begin{array}{l}\text { Total hazard } \\
\text { trees found by } \\
\text { by walking survey }\end{array}$ & $\begin{array}{l}\text { Percentage of walking } \\
\text { survey hazard trees found } \\
\text { by windshield survey }\end{array}$ \\
\hline $7-12$ & 94 & $58 \%$ \\
$8-12$ & 55 & $69 \%$ \\
$9-12$ & 30 & $79 \%$ \\
$10-12$ & 17 & $89 \%$ \\
\hline
\end{tabular}

\section{Developed/Undeveloped Analysis}

For developed areas, the number of hazard trees found by the windshield survey expressed as a percentage of hazard trees found by the walking survey ranged from $66 \%$ at hazard rating $\geq 7$ to $100 \%$ for hazard rating $\geq 10$ (Table 6). Hazard ratings were generally lower in undeveloped sections.

Table 6. Number of hazard trees found by windshield survey expressed as a percentage of hazard trees found by walking survey, arranged by area. Developed and undeveloped areas are explained in the text. There were insufficient trees rated $\geq 10$ in undeveloped areas to provide a percentage.

\begin{tabular}{lll}
\hline Hazard rating & Developed areas & Undeveloped areas \\
\hline $7-12$ & $66 \%$ & $49 \%$ \\
$8-12$ & $81 \%$ & $50 \%$ \\
$9-12$ & $96 \%$ & $50 \%$ \\
$10-12$ & $100 \%$ & $\mathrm{n} / \mathrm{a}$ \\
\hline
\end{tabular}

\section{DISCUSSION}

The windshield survey of the town took longer than anticipated. This was due to many factors, including bad weather, available volunteer time, and the high number of hazard trees that were ultimately identified.

Comparing the windshield surveys and the walking survey indicates that as the tree hazard became more severe, the chance of finding it by using a windshield survey increased. This result lends a degree of confidence in using windshield surveys to identify hazard trees, but only in cases of high hazards. Considering that in many situations, a community can remedy only the most severe hazards, the windshield survey could be an effective method for assessing community trees for hazard.

In the developed sample areas, the percentage of high hazard trees found using the windshield survey was higher than in undeveloped sample areas. This could occur for many reasons. The developed sections usually had trees that stood by themselves on the side of the road, which facilitated inspection. The inspector could examine these trees continuously, which enabled him to have a longer look at the same tree without having to examine another. In many cases, nearly the entire structure of the tree could be seen in developed areas because of the cleaner roadside environment. In undeveloped wooded areas, leaf piles, brush, or vines obstructed a complete view of the tree. The lessobstructed view in developed areas may have allowed more hazards to be identified.

Several factors affected the windshield survey. First, the drivers improved each time they volunteered because the inspector and driver learned to work together. Primary concerns included the inspector deciding whether it was necessary to slow down as the vehicle approached a questionable tree. After repeated surveys, volunteer drivers and the inspector worked better together. In some cases, the driver would anticipate the next tree to examine and would slow down accordingly. A second factor that affected the windshield survey was inclement weather. During winter 2002-2003, South Kingstown received more snow than in the previous three winters combined, accumulating $143 \mathrm{~cm}$ (56 in.). The snow made surveys much more difficult. This factor is important for communities that receive high snowfall. Because the root flare needs to be seen during surveying, a snow pack would prohibit the examination of this area. A third factor that affected the windshield survey was driving speed. The speed at which surveys were completed was directly related to the traffic in the area, tree density, and quality of the trees. The speed at which surveys were conducted was inversely proportional to the amount of vehicular and pedestrian traffic. Survey speed was also inversely proportional to the number of trees on the street. The presence of multiple targets and severe defects similarly slowed surveying. 
The surveyed community had many poor-quality trees with multiple hazardous conditions. This dramatically slowed progress in some areas. The community was chosen because it was thought that the town's tree population would have enough hazard trees to effectively test the project's windshield survey, unfortunately the community had even more than anticipated. A windshield survey of a community that continuously maintains their trees will progress much faster.

\section{CONCLUSIONS}

This study showed that hazardous conditions can be discovered using a windshield survey in the community studied. For this study, minimal training was conducted for the drivers and inspector, and some of the missed hazardous tree conditions presumably would have been discovered with more practice and experience. The proper training of drivers is needed to ensure that trees are not passed without examination.

The main factor in deciding when and where to use the windshield survey is efficiency. These following conditions can assist in determining when it is appropriate to use windshield surveys. The windshield survey worked well in low-traffic areas. In high-traffic, areas the drivers and surveyor became concerned about the traffic. This caused some disruptions of the survey. In high-traffic areas, walking or using other means, such as a bicycle to move from tree to tree, would be advisable.

Another consideration is the degree of maintenance the trees receive and their average condition. Some of the roads in South Kingstown had many trees in poor shape and with many hazardous conditions. This dramatically slowed the survey. If the trees are not well maintained, a thorough inventory may be the best choice. If the trees are reasonably maintained, the windshield survey could be used just to locate quickly developing hazardous conditions such as hanging branches or recent storm damage, or for an annual update of streetside conditions.

\section{LITERATURE CITED}

Grey, G.W., and FJ. Deneke. 1978. Urban Forestry. John Wiley. New York, NY.

Lilly, S.J. 2001. Arborists' Certification Study Guide. International Society of Arboriculture, Champaign, IL.

Kane, B., H.D.P Ryan III, and D.V. Bloniarz. 2001. Prioritizing risk trees in a community. Tree Care Industry 12(7):45-51.

Pokorny, J.D. 2003. Urban Tree Risk Management: A Community Guide to Program Design and Implementation. USDA Forest Service, Northeastern Area, St. Paul, MN. www.na.fs.fed.us/spfo/pubs/uf/utrmm (accessed 2/1/05).
Sandfort, S., 2001. A Common Sense Approach to Street Tree Inventories. Tree Care Industry 12(9):41-42, 44, $46,49$.

Smiley, E.T., and B.R. Fraedrich. 1991. Hazardous Tree Evaluation and Management. The Bartlett Tree Expert Company, Charlotte, NC.

National Park Service. 1991. Hazard Tree Guidelines. Natural Resources Management Guideline No. NPS-77. U.S. Department of the Interior, National Park Service, Natural Resources Office. www.na.fs.fed.us/spfo/ hazard.nps.htm (accessed 2/1/05).

Acknowledgments. This project was partially funded through a John Z. Duling grant from the TREE Fund. The authors acknowledge the helpful comments from three anonymous reviewers.

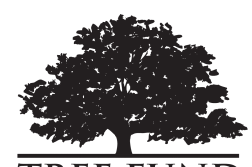

TREE FUND Tree Research \& Education Endowment Fun

${ }^{1 *}$ Arborist

The Narragansett Electric Company/A National Grid Company 280 Melrose Street

Providence, RI 02807, U.S.

${ }^{2}$ Professor of Arboriculture and Community Forestry

University of Massachusetts at Amherst

Holdsworth NRC

Amherst, MA 01003, U.S.

${ }^{3}$ Urban Forester

USDA Forest Service

Northeast Center for Urban and Community Forestry

Holdsworth NRC

Amherst, MA 01003, U.S.

${ }^{4}$ MAA Professor of Commercial Arboriculture

University of Massachusetts at Amherst

Holdsworth NRC

Amherst, MA 01003, U.S.

"Corresponding author. 
Résumé. Les conditions de risques des arbres de rues sont un sujet constant de préoccupation pour les arboriculteurs municipaux. En raison de contraintes fiscales, plusieurs municipalités veulent une méthode précise et efficace pour inspecter leur population d'arbres. Cette étude de cas présente une méthode d'inventaire au moyen d'une auto qui peut être utilisée pour détecter les situations à risques sur les arbres de rues, et ce en utilisant une méthodologie simple et l'expérience d'un arboriculteur certifié. De plus, cet exemple de cas permet de démontrer que le pourcentage de conditions dangereuses détectées s'accroît lorsque la condition des arbres devient plus sévère. Le pourcentage d'arbres dangereux détectés au moyen d'un inventaire en auto était plus important dans les secteurs d'échantillonnage de zones développées que lorsque l'on était dans les secteurs d'échantillonnage de zones non développées.

Zusammenfassung. Die Gefahrbringenden Zustände von Straßenbäumen sind eine ständige Sorge für die städtische Baumpflege. Wegen finanzieller Einschränkungen haben viele Stadtverwaltungen den Wunsch nach einer akkuraten und effizienten Methode, die Bäume zu überwachen. Diese Fallstudie zeigt, dass eine Windschutzstudie genutzt werden kann, um die
Gefahrbringenden Zustände von Straßenbäumen aufzuzeigen, indem ein einfaches System und ein qualifizierter, erfahrener Baumpfleger einbezogen werden. Zusätzlich zeigte die Fallstudie, dass der Prozentsatz von aufgezeigten Gefahrbringenden Bäumen anstieg, als die Zustände ernster wurden. Der Prozentsatz von aufgezeigten Gefahrbringenden Bäumen durch die Windschutzstudie in entwickelten Probeflächen überstieg weit die der gefundenen Bäume in unentwickelten Probeflächen.

Resumen. Las condiciones de riesgo con árboles en las carreteras son una preocupación constante para los arboristas municipales. Debido a obligaciones fiscales, muchas municipalidades desean precisar y hacer eficiente el método para inspeccionar sus poblaciones de árboles. Este caso de estudio muestra que un relevamiento rápido, desde un vehículo, puede ser usado para encontrar condiciones peligrosas en árboles de las carreteras, usando un sistema simple y un arborista certificado con experiencia. Además, el caso de estudio mostró que el porcentaje de situaciones riesgosas detectadas incrementó a medida que estas condiciones fueron más severas. El porcentaje de condiciones riesgosas con los árboles encontrados, usando un inventario rápido en áreas de muestreo, excedió al de áreas sin desarrollo. 